\title{
The Effect of Motivation and Attention on Bias in Memory for Duration
}

\author{
Sebastian Schwab ${ }^{1}$, Daniel Memmert ${ }^{1}$, Michael M. Roy ${ }^{2}$ \\ ${ }^{1}$ Institute of Cognitive and Team/Racket Sport Research, German Sport University, Cologne, Germany \\ ${ }^{2}$ Department of Psychology, Elizabethtown College, Elizabethtown, USA \\ Email: s.schwab@dshs-koeln.de
}

Received October $30^{\text {th }}, 2012$; revised November $29^{\text {th }}, 2012$; accepted December $23^{\text {rd }}, 2012$

\begin{abstract}
In the present study, we investigated the effect of regulatory focus on bias in memory for task duration. Specifically, whether or not a person's motivational outlook, seeking gains or avoiding losses, would cause them to over- or underestimate task duration. Eighty-four college students completed an origami task for which motivational focus (gains or losses), experience with the task and amount of attention directed to the task were manipulated. Participants with a focus on seeking gains tended to remember the task as taking less time when their attention was drawn towards the details of the task instead of away from the task than did participants in the other conditions. It seems that this effect occurred because participants with a focus for seeking gains did not sufficiently account for the fact that drawing attention toward the task caused them to take longer on the task than on previous trials.
\end{abstract}

Keywords: Motivation; Attention; Regulatory Focus; Time Estimation

\section{Introduction}

People are often inaccurate and biased when estimating previous task duration (Block \& Zakay, 1997; Fraisse, 1963; Roy, Christenfeld, \& McKenzie, 2005). Task variables, such as whether or not the interval was filled or unfilled (Wearden, Norton, Martin, \& Montford-Bebb, 2007) or relatively short or long (Roy \& Christenfeld, 2008; Vierordt, 1868), can influence size and direction of participants' bias in estimates of previous task duration. Similarly, person variables, such as emotional state, can also influence their memory for previous task duration (Droit-Volet \& Gil, 2009). More important to the current research, a person's motivations can influence remembered duration; participants were more likely to remember quicker completion times when they were told that quick task performance reflected intellectual ability than when they were told that the task was an innocuous game (Meade, 1963). Also, people with high intrinsic motivation are more likely than people with low intrinsic motivation to underestimate how much time has passed (Conti, 2001). Here we examine whether or not a person's motivational focus can influence memory for past task duration.

Higgins (1997) proposed that there are two distinct motivetional states (regulatory focus), a promotion focus centered on accomplishments and aspirations and a prevention focus concerned with safety and responsibilities. People with a promotion focus seek gains while people with a prevention focus try to avoid losses. Motivational focus has been found to influence cognitive processes such as the ability to learn classification rules (Markman, Baldwin, \& Maddox, 2005) and recognize previously learned words (Crowe \& Higgins, 1997). In general, people with a promotion focus tend to be more flexible and inventive in their thought processes (Friedman \& Förster, 2001). Regulatory focus has also been tied to a person's sense of time, with shifts in regulatory focus changing perception of distance to future events (Pennington \& Roese, 2003).

Here we examine whether a promotion or prevention focus influences duration memory for already completed tasks. Shifts in regulatory focus have been found to cause corresponding shifts in attentional focus with promotion focus leading to a broad focus and a prevention focus leading to a narrow a focus (Förster \& Higgins, 2005). For example, participants completing a Navon (1977) task (an identification task using a large letter made up of smaller letters) could identify the large letter quicker in a promotion mode and the small letters quicker in a prevention mode (Förster, Friedman, Özelsel, \& Denzler, 2006; Förster \& Higgins, 2005). A shift in attention can influence time perception: at times, increasing attention to a task can cause a corresponding decrease in experienced task duration (Thomas \& Weaver, 1975; Zakay \& Block, 1997). Increased attention to the task can cause participants to pay more attention to the task and less on time in passing and, as a result, experience the task as taking less time (Zakay \& Block, 1997). Therefore, a prevention focus (narrow focus on the task) could cause participants to pay less attention to time in passing and underestimate duration. A promotion focus (broad focus) would likely leave more attentional resources available for monitoring time and lead to longer estimates.

However, attentional models of time estimation (Thomas \& Weaver, 1975) best explain perception for time in passing, and not memory for past duration (Zakay \& Block, 1997). It is possible that directed attention due to a prevention focus might cause participants to remember more details of the tasks in retrospect, with more remembered items or changes making the task seem to have taken longer. When asked to estimate duration retrospectively, people may use amount of memory associated with the task or number of changes remembered to help estimate task duration (Block \& Reed, 1978; Ornstein, 1969; Zakay \& Block, 1997). If a shift in regulatory focus influences memory for the details of the task, or how many details of the 
task are encoded while performing the task, then participants with a promotion focus (broad attentional focus shifting focus away from the task) should remember that task as taking less time than do participants with a prevention focus (narrow focus). Participants would have paid attention to more of the details of the task, creating more elaborate memories, which, in turn, cause longer estimates of duration.

To examine the impact of motivational focus on attention, we manipulated both participants' motivational focus and also the amount of attention that they paid to the task. Attention to the task was manipulated both indirectly and directly. As an indirect manipulation of attention, level of experience with the task was varied. As people become more familiar with a task, attention shifts from the components of the task to the overall outcomes (Wulf, 2007). A shift in attention could explain why novices are more likely to overestimate task duration while experts are more likely to underestimate task duration (Boltz, Kuppermann, \& Dunne, 1998; Hinds, 1999; Roy \& Christenfeld, 2007). For example, Roy and Christenfeld (2007) found that increasing experience with an origami task led estimation to move from overestimation when participants were new to the task to underestimation when participants were familiar with the task. Novices may have paid more attention to the small details, while experts focused more on end quality. Consequently, it might be expected that novices would be less likely to overestimate when given a promotion focus, changing from a narrow to a broad focus, while experts would be less likely to underestimate when given a prevention focus, changing from a broad to a narrow focus.

To directly manipulate participants' attentional focus, participants' attention was drawn toward or away from the specifics of the task. Previous research has found that novices seem to do better on a motor task when their attention is drawn toward the task while experts tend to do better when their attention is diverted away from the task (Beilock, Bertenthal, McCoy, \& Carr, 2004). Here, we might expect the effect of a broad focus caused by a promotion orientation to be lessened when the participants' attention is drawn toward the task. In contrast, a narrow focus, caused by a prevention orientation, might be lessened when attention is drawn away from the task.

In summary, the aim of this study was to examine the influence of promotional focus on time estimation. Further, we examined if the potential influence of promotional focus on bias in time estimation was caused by a shift in attention paid to the tasks. Participants performed an origami task while regulatory focus, amount of experience with the task, and level of attention towards the task were manipulated. We hypothesized that participants with a promotion focus would remember the origami task as taking less time than someone with a prevention focus due to a shift in attention away from the details of the task.

\section{Method}

\section{Participants}

Eighty-four students from the University of Heidelberg and the German Sport University Cologne (40 female) aged 18 - 32 years $(M=24.0)$ participated voluntarily in this experiment. Only a few participants had experience making origami objects and their inclusion did not change the results. Informed consent was obtained from every participant before commencing the experiment in accordance with the Helsinki Declaration of 1975.

\section{Materials and Design}

The experiment was a 2 (experience) $\times 2$ (regulatory focus) $\times 2$ (attention) design. Participants either had no practice making origami rabbits (low experience) or made nine practice rabbits (high experience) before performing two test trials. Participants then received either a promotion or prevention manipulation before their first test trial rabbit. Finally, participants were given an external or internal attention manipulation before their last test trial with attention directed either away from or toward the task. The regulatory focus and attention manipulations were spread out over two trials so that participants were not overwhelmed with directions. In the end, participants were asked to estimate the duration of the last test trial. The origami task was chosen because, in a pilot study, there was an interaction between experience and attention for the task (as in the Beilock et al., 2004, study), with attention away from the task hurting novices (making them slower) and helping experts (making them faster) and attention toward the task helping novices and hurting experts.

\section{Procedure}

Participants first drew lots that determined their condition for the regulatory focus and attention manipulations. Then participants either made nine practice rabbits or were not given any practice. Participants making practice rabbits were given an example origami rabbit and written instructions to examine. They were next given the appropriate number of sheets of paper, a pair of scissors and a pen. The same procedures were followed for the participants in the no practice group before they made their first rabbit.

Participants in the promotion condition (seeking gains) were verbally told: "If you perform better than $50 \%$ of all participants both in accuracy - evaluated by an origami expert - and in speed, you will get a lottery ticket." The lottery ticket was for the state run lottery giving participants a chance to win millions of Euros, dependent on luck and the size of the jackpot. The investigator then held up a lottery ticket for them to view. Participants in the prevention condition (avoiding losses) were told: "If you perform worse than $50 \%$ of all participants both in accuracy - evaluated by an origami-expert - and in speed, you will lose a lottery ticket, which otherwise would be yours." Following this instruction, the investigator gave them a lottery ticket. All participants were given a lottery ticket by the end of the task. A similar manipulation has been found to alter regulatory focus in previous experiments (Maddox, Baldwin, \& Markman, 2005; Shah, Higgins, \& Friedman, 1998). After the regulatory focus manipulation, participants were asked to make an origami rabbit as accurately and quickly as possible. Participants were made aware that they would be timed.

The attentional focus manipulation was introduced before the final trial. Participants in the internal/play-by-play condition were instructed: "Now I want you to make one more rabbit, but I want you to describe what you are doing while making the rabbit - like a play-by-play announcer would on TV. Try not to let your commentary interrupt the folding of the rabbit." Participants in the external attention condition were instructed: "I am going to play a tape that has tones on it, high and low, and I am going to have you monitor the tones while you are making another rabbit. Here is an example of the two tones." The investigator played the tape of the first two tones and stopped the tape. "What I want you to do is say 'high' when you hear the 
high tone and disregard the low tone." See Beilock, Carr, MacMahon \& Starkes (2002) for a study using a similar manipulation. In both conditions, the investigator handed the participants the materials and timed the trial. After finishing this second test trial, the participants were asked to estimate in minutes and seconds duration of the last trial.

\section{Measures}

An index of estimation bias was created by taking the log of the ratio of estimated duration to actual duration, which we will call log proportional error (Roy \& Christenfeld, 2007, 2008). Here, actual duration was the time it took the participant to complete the second test trial. This index helps to simplify interpretation; a negative score indicates underestimation, a score of zero indicates perfect accuracy, and a positive score indicates overestimation. The index also normalizes the data; there was, as is generally found, a strong positive skew in estimates of duration. In addition, this index allows a comparison of the bias in estimates across tasks of different lengths.

\section{Results and Discussion}

\section{Effect of Condition on Performance}

While we were mainly interested in the influence of motivetional focus on bias, we first examined the influence of the manipulations on actual duration. Differences in task duration can cause corresponding shifts in bias (Roy \& Christenfeld, 2008).

On the first test trial, participants in the low experience condition took $234.6 \mathrm{sec}$ to make the origami rabbit, while participants in the high experience condition took $94.8 \mathrm{sec}$ (see Table 1 for full results). A 2 (experience) $\times 2$ (regulatory focus) ANOVA on actual duration revealed a significant difference in time needed to complete the task due to level of experience $F(1$, $80)=132.1, p<.001, \eta_{p}^{2}=.62$. There was no effect of the regulatory focus manipulation on time needed to complete the task and no interaction between focus and expertise, $F_{\mathrm{s}}<.5, p \mathrm{~s}$ $>.5$.

For the second trial, a 2 (experience) $\times 2$ (regulatory focus $) \times$ 2 (attention) ANOVA on actual duration indicated a significant main effect of experience $F(1,76)=18.6, p<.001, \eta_{P}^{2}=.20$, with low experience participants $(M=159.6 \mathrm{sec})$ taking longer than high experience participants $(M=108.0 \mathrm{sec})$. Here, there was also a main effect of attention $F(1,76)=5.19, p=.026$,
$\eta_{P}^{2}=.06$, with participants in the play-by-play (internal) condition $(M=147.0 \mathrm{sec})$ taking longer than participants in the tones (external) condition $(M=121.2 \mathrm{sec})$. There was no main effect of regulatory focus, and there were no significant 2-way or 3-way interactions $F \mathrm{~s}<1.6, p \mathrm{~s}>.2$.

Unlike previous research (Beilock et al., 2002, 2004), including our pilot study, there was no interaction between level of experience and attentional focus: participants both low and high in experience performed slower when attention was directed toward the task. It is unclear why, for our experiment, that drawing attention to the task caused performance to be worse. It may be, for example, that it was difficult for participants to find proper terms to describe their actions. To a certain degree, however, the direction of change in performance due to the manipulation might not be as important as whether or not participants recognized that the manipulation altered their performance.

\section{Effect of Condition on Bias}

Of central interest, there was an effect of the regulatory focus and attention manipulations on bias. A $2 \times 2 \times 2$ ANOVA on bias (log proportional error) showed, as has been found previously (Boltz et al., 1998; Roy \& Christenfeld, 2007), a significant main effect of experience with low experience participants more likely to overestimate task duration and high experience participants more likely to underestimate $F(1,76)=53.8, p$ $<.001, \eta_{p}^{2}=.42$. There was also a significant two-way interaction between focus and attention $F(1,76)=4.41, p=.04, \quad \eta_{P}^{2}$ $=.06$ : participants that received both the promotion and internal focus manipulations were less likely to overestimate task duration if they had low experience with the task and were more likely to underestimate duration if they had high experience (see Table 1). Simple effect tests indicate that participants with a promotion focus were significantly more biased toward underestimation in the internal condition $(M=-.061)$ than in the external condition $\left(M=.032, p=.044, \eta_{P}^{2}=.05\right)$ and that participants with an internal focus tended to be more biased toward underestimation when they had a promotion focus rather than a prevention focus $\left(M=.027, p=.056 \eta_{p}^{2}=.05\right)$. Other simple effects were not significant $(p s>.3)$. Overall, participants in the promotion condition were more likely to be biased towards underestimation in the internal condition. All other main effects and interactions for bias (log proportional error) were not significant $(F \mathrm{~s}<1.1, p \mathrm{~s}>.3)$. While previous research

Table 1.

Time needed (in seconds) to complete the first rabbit, the second rabbit, the estimated duration for the second rabbit, and bias (log proportional error) for the estimate (with standard error).

\begin{tabular}{|c|c|c|c|c|c|c|}
\hline Experience Level & Regulatory Focus & Attentional Focus & Actual Duration First Trial & $\begin{array}{c}\text { Actual Duration } \\
\text { Second Trial }\end{array}$ & $\begin{array}{l}\text { Estimated Duration } \\
\text { Second Trial }\end{array}$ & Bias (LPE) \\
\hline \multirow{4}{*}{ Low Experience } & \multirow{2}{*}{ Promotion } & Internal & $226.8(27.6)$ & $171.0(19.8)$ & $232.8(45.6)$ & $.07(.07)$ \\
\hline & & External & $231.0(11.4)$ & $162.0(13.2)$ & $223.8(21.6)$ & $.14(.03)$ \\
\hline & \multirow{2}{*}{ Prevention } & Internal & $252.0(22.8)$ & $166.2(10.8)$ & $228.0(23.4)$ & $.13(.02)$ \\
\hline & & External & $228.0(28.2)$ & $139.2(14.4)$ & $190.2(30.0)$ & $.12(.04)$ \\
\hline \multirow{4}{*}{ High Experience } & \multirow{2}{*}{ Promotion } & Internal & $87.0(7.8)$ & $112.8(10.8)$ & $73.8(7.8)$ & $-.19(.05)$ \\
\hline & & External & $96.0(10.2)$ & $99.0(7.2)$ & $85.8(9.6)$ & $-.07(.03)$ \\
\hline & \multirow{2}{*}{ Prevention } & Internal & $100.8(13.8)$ & $142.2(28.8)$ & $121.8(24.0)$ & $-.07(.05)$ \\
\hline & & External & $91.8(8.4)$ & $91.2(9.0)$ & $67.8(9.0)$ & $-.15(.05)$ \\
\hline
\end{tabular}


has found that task duration can affect size of bias (Roy \& Christenfeld, 2008), adding actual task duration as a covariate to the above analysis did not alter the results.

It is possible that the increased tendency to underestimate when the promotion and internal focus conditions were combined was because participants with a promotion motivation did not account for the fact that performing the play-by-play condition forced them to take longer at the task. In support, when given both the promotion and internal focus manipulations, participants' overall error (absolute value of the difference between their estimate and the actual duration) was smaller when their estimate was compared to their first trial, $M=40.2 \mathrm{sec}$, than when compared to their second trial (which they were actually estimating), $M=67.2 \mathrm{sec}, t(20)=2.13, p=.04, d=.46$. However, this same relationship was not true in the other three conditions: there was no significant difference in overall error when comparing participants' estimates to either completion time $(p s>.4)$. In the promotion condition, estimated duration appeared to be more influenced by previous trials than the trial that was actually being estimated.

\section{General Discussion}

While regulatory focus did influence time perception with a shift in attention likely causing this influence, the connection between motivation and attention were not as we originally envisioned. We thought that having a promotion or prevention focus might cause a shift in attention to the task at more of a micro level, with people high in prevention paying more attention to the small details of the tasks. Instead, a shift in regulatory focus appears to influence attention to the task at more of a macro level: participants with a promotion focus did not pay attention to changes in the task that caused it to take longer.

Given that previous research has found that people with a promotion focus are more attuned to the big picture and not the small details (Förster \& Higgins, 2005), we speculated that a promotion focus would change how participants experienced the details of the task. Participants might have been less likely to attend to the specifics of the tasks causing longer estimates due to decreased attention spent monitoring time in passing (Thomas \& Weaver, 1975; Zakay \& Block, 1997) or participants might have remembered less specifics of the task causing shorter estimates due to less attention paid to details of the task during performance (Block \& Reed, 1978; Ornstein, 1969; Zakay \& Block, 1997). However, these explanations are not consistent with our finding that the tendency toward underestimation was greatest only when a promotion focus was combined with an internal focus. If motivational focus influenced attention or memory for the specifics of the task, then bias should have been largest when focus was very broad (promotion and external focus) or very narrow (prevention and internal focus). Instead, there was a differential effect of promotion focus for the internal and external conditions indicating that the results cannot simply be explained in terms of participants paying less attention or remembering less of the specifics of the task.

The influence of a promotion focus was only evident on the task at a macro level that included the participants' full experience with the task. The tendency to remember the origami task as being shorter when given both the promotion and internal focus manipulations can be explained by insufficient adjustment from previous experience with the task. The internal focus manipulation caused participants to take longer on the task or, in the case of participants with low experience, improve less. Participants did not seem to take this into account retrospecttively when they had a promotion focus, which causes people to look at the big picture and not the details (Förster \& Higgins, 2005). Therefore, if participants were trying to reconstruct their memory by focusing first on what they consider the prototypical duration of the task and then adjusting for aspects of the task that might have made it take longer or shorter (Bartlett, 1932; Burt, 1992), a promotion focus appears to have caused them to make an insufficient adjustment from the prototype. Participants with a prevention focus, who likely paid more attention to changes in the task, were able to make a sufficient adjustment. When a promotion focus was combined with an internal focus, which increased task duration, participants remembered the task as taking less time than did others with similar experience. In contrast, when a promotion focus was combined with an external focus, which did not alter task completion times, there was no shift in bias. Attention, or lack of attention to be precise, to changes in the task led to bias in remembered duration.

The results of the current study indicate that a person's motivational focus can influence their memory for task duration. This seems to be limited to situations where the task takes longer or shorter than it has previously. Participants who were focused on seeking gains appeared to ignore the circumstances that caused a change in the task and, therefore, were more likely to differ in bias from others. Participants that were high in experience with making origami rabbits were most likely to underestimate the duration. For novices with origami task, the shift in regulatory focus actually led to a more positive outcome with a promotion focus leading to a decrease in the tendency to overestimate.

\section{Acknowledgements}

We thank Nina Heinen, Katharina Kurz, Katharina Mayerle, Ekaterini Nasta, Martina Herma, Saskia Sekanina and Teresa Stegmüller for their help collecting the data.

\section{REFERENCES}

Bartlett, F. (1932). Remembering: A study in experimental and social psychology. Cambridge: Cambridge University Press.

Beilock, S. L., Carr, T. H., MacMahon, C., \& Starkes, J. L. (2002). When paying attention becomes counterproductive: Impact of divided versus skill-focused attention on novice and experienced performance of sensorimotor skills. Journal of Experimental Psychology: Applied, 8, 6-16. doi:10.1037/1076-898X.8.1.6

Beilock, S. L., Bertenthal, B. I., McCoy, A. M., \& Carr, T. H. (2004). Haste does not always make waste: Expertise, direction of attention, and speed versus accuracy in performing sensory motor skills. Psychonomic Bulletin \& Review, 11, 373-379. doi:10.3758/BF03196585

Block, R. A., \& Reed, M. A. (1978). Remernbered duration: Evidence for a contextual-change hypothesis. Journal of Experimental Psychology: Human Learning and Memory, 4, 656-665. doi:10.1037/0278-7393.4.6.656

Block, R. A., \& Zakay, D. (1997). Prospective and retrospective durations judgments: A meta-analytic review. Psychonomic Bulletin \& Review, 4, 184-197. doi:10.3758/BF03209393

Boltz, M. G., Kuppermann, C., \& Dunne, J. (1998). The role of learn-ing in remembered duration. Memory \& Cognition, 26, 903-921. doi:10.3758/BF03201172

Burt, C. D. B. (1992). Reconstruction of the duration of autobiographi- 
cal events. Memory and Cognition, 20, 124-132. doi:10.3758/BF03197160

Conti, R. (2001). Time flies: Investigating the connection between intrinsic motivation and the experience of time. Journal of Personality, 69, 1-26. doi:10.1111/1467-6494.00134

Crowe, E., \& Higgins, E. T. (1997). Regulatory focus and strategic inclinations: Promotion and prevention in decision making. Organizational Behavior and Human Decision Processes, 69, 117-132. doi:10.1006/obhd.1996.2675

Droit-Volet, S., \& Gil, S. (2009). The time-emotion paradox. Philosophical Transactions of the Royal Society B, 364, 1943-1953. doi: $10.1098 /$ rstb.2009.0013

Förster, J., \& Higgins, E. T. (2005). How global vs. local processing fits regulatory focus. Psychological Science, 16, 631-636. doi:10.1111/j.1467-9280.2005.01586.x

Förster, J., Friedman, R. S., Özelsel, A., \& Denzler, M. (2006). Enactment of approach and avoidance behavior influences the scope of perceptual and conceptual attention. Journal of Experimental Social Psychology, 42, 133-146. doi:10.1016/j.jesp.2005.02.004

Fraisse, P. (1963). The psychology of time. New York: Harper \& Row.

Friedman, R. S., \& Förster, J. (2001). The effects of promotion and prevention cues on creativity. Journal of Personality and Social Psychology, 81, 1001-1013. doi:10.1037/0022-3514.81.6.1001

Higgins, E. T. (1997). Beyond pleasure and pain. American Psychologist, 52, 1280-1013. doi:10.1037/0003-066X.52.12.1280

Hinds, P. J. (1999). The curse of expertise: The effects of expertise and debiasing methods on predictions of novice performance. Journal of Experimental Psychology: Applied, 5, 205-221. doi:10.1037/1076-898X.5.2.205

Markman, A. B., Baldwin, G. C., \& Maddox, W. T. (2005). The interaction of payoff structure and regulatory focus in classification. Psychological Science, 16, 852-855. doi:10.1111/j.1467-9280.2005.01625.x

Meade, R. D. (1963). Effect of motivation and progress on the estimation of longer time intervals. Journal of Experimental Psychology, 65, 564-567. doi: $10.1037 / \mathrm{h} 0046552$
Navon, D. (1977). Forest before trees: The precedence of global features in visual perception. Cognitive Psychology, 9, 353-383.

Ornstein, R. E. (1969). On the experience of time. Middlesex: Penguin Books. doi:10.1016/0010-0285(77)90012-3

Pennington, G. L., \& Roese, N. J. (2003). Regulatory focus and temporal distance. Journal of Experimental Social Psychology, 39, 563-576. doi:10.1016/S0022-1031(03)00058-1

Roy, M. M., \& Christenfeld, N .J. S. (2007). Bias in memory predicts bias in estimation of future task duration. Memory \& Cognition, 35, 557-564. doi:10.3758/BF03193294

Roy, M. M., \& Christenfeld, N. J. S. (2008). Effect of task length on remembered and predicted duration. Psychonomic Bulletin \& Review, 15, 202-207. doi:10.3758/PBR.15.1.202

Roy, M. M., Christenfeld, N. J. S., \& McKenzie, C. R. M. (2005). Underestimation of future duration: Memory incorrectly used or memory bias. Psychological Bulletin, 131, 738-756. doi: $10.1037 / 0033-2909.131 .5 .738$

Shah, J., \& Higgins, E. T. (1997). Expectancy $\times$ value effects: Regulatory focus as determinant of magnitude and direction. Journal of Personality and Social Psychology, 73, 447-458. doi:10.1037/0022-3514.73.3.447

Thomas, E. A. C., \& Weaver, W. B. (1975). Cognitive processing and time perception. Perception and Psychophysics, 17, 363-367. doi:10.3758/BF03199347

Vierordt, K. (1868). Der zeitsinn nach versuchen. Tubingen: H. Laupp.

Wearden, J. H., Norton, R., Martin, S., \& Montford-Bebb, O. (2007). Internal clock processes and the filled-duration illusion. Journal of Experimental Psychology: Human Perception and Performance, 33, 716-729. doi:10.1037/0096-1523.33.3.716

Wulf, G. (2007). Attention and motor skill learning. Leeds: Human Kinetics.

Zakay, D., \& Block, R. A. (1997). Temporal cognition. Current Directions in Psychological Science, 6, 12-16. doi:10.1111/1467-8721.ep11512604 